\title{
Mediation as a Leadership Strategy to Deal with Conflict in Schools
}

\author{
Maitumeleng Albertina Ntho-Ntho ${ }^{1, *}$ \& Frederik Jan Nieuwenhuis ${ }^{1}$ \\ ${ }^{1}$ Department of Humanities Education, Faculty of Education, University of Pretoria, Pretoria, South Africa \\ *Correspondence: Department of Humanities Education, Faculty of Education, University of Pretoria, Pretoria, \\ South Africa. Tel: 27-12-420-5571. E-mail: mnthontho2010@webmail.co.za
}

Received: April 11, 2016

Accepted: May 18, 2016 Online Published: August 12, 2016

doi:10.5430/jct.v5n2p13

URL: http://dx.doi.org/10.5430/jct.v5n2p13

\begin{abstract}
The concept of mediation is a process that is frequently used in the labour field and is under-developed in a field such as education. Mediation as a strategy to resolve conflict in an amicable way has gained support in various other fields but seems not to be seen as a mainstream solution to resolving conflict in education. This article reports on a qualitative study whose aim was to explore how the South African school principals deal with religious interest conflicts in their schools. The study employed narrative interviews as a means of data collection. Stories of twelve school principals pursuing postgraduate studies at the University of Pretoria, all of whom had been in education for at least fifteen years at the time of the study, were collected, transcribed, analyzed and interpreted. The study revealed that none of the principals in the study saw mediation as a conducive strategy for conflict resolution, instead; they resisted and ignored the new religion policy. We therefore suggest that for effective implementation of new policies, certain strategies must be popularised within schools. We further recommend possible application of the concept of mediation as a leadership strategy in dealing with conflict in schools.
\end{abstract}

Keywords: conflict; conflict management; educational policy change; leadership strategy; mediation

\section{Introduction}

The South African government brought to place the National Policy on Religion and Education on the $4^{\text {th }}$ of August, 2003. Its intention was to encourage schools to promote reconciliation - to bridge the religious divide through a greater understanding of others (DoE, 2001), to ensure peace and tolerance amongst learners belonging to widely different religious affiliations (Abdool et al.., 2007), to help learners understand the colourful religious heritage of the country, thus developing respect for other human beings while simultaneously closing the geographical and religious gap between various communities in the country - a space created in the name of civilisation and Christianity (Mkhatshwa,1998). Put differently, the ultimate aim of the policy is to promote religious freedom, pluralism, diversity, tolerance, respect, justice, compassion and commitment in young South Africans (DoE, 2001).

It is however worth noting that the policy was delayed until 2003 due to lengthy and highly charged debates. In spite of its clearly educational aims, the religion-in-education policy provoked a storm of controversy (Chisholm, 2005). According to Roux (2001), attempts and initiatives to change the religion education programmes in schools were received with hostility by many individuals and groups in the religious, educational and public spheres.

It is in the context of this kind of friction that we would argue that school principals have a very special role to fulfil, that of reconciling disparate views of the stakeholder groupings. Unless they are able to do so it is highly likely that the smooth running of their schools will be disrupted. In the South African context and that of many countries, principals, by virtue of their position as heads of their schools, are pivotal to the implementation of school-based reform. The structural arrangement which requires them to both head the School Management Team (SMT) and to ex-officio represent the department of education in school governing body (SGB) deliberations (Naidoo, 2005) implies that the ultimate responsibility for managing the proposed changes lies in their hands. The principal, not the SGB, is the key figure, the catalyst, and the change agent around which much of the school's activities revolve (Fullan, 2007). In practical terms, in his capacity as the professional leader, the school principal has to do everything possible to ensure that the conduct of the school governing body and of the provincial education departments is lawful, fair and reasonable (Joubert \& Prinsloo, 2009). By implication, he/she has to watch over the interests of the provincial 
education departments when functioning as a school governing body member and over the interests of the governing body when dealing with provincial education departments and this according to this study, is where the conflict originates.

\section{The Nature and Origin of Conflict}

In terms of Section 1 of the Constitution of South Africa (Act 108 of 1996), the primary aim of the Constitution is to establish a representative democracy, supplemented by direct and participatory governance - that is, a democracy in which people participate not only in governance decisions that affect them but also when they are asked to make decisions on other matters (Joubert \& Prinsloo, 2009). The Constitution further pronounces that "[e]veryone has the right to freedom of conscience, religion, thought, belief and opinion" (Section 15 (1)). Section 15 (2) points out that religious observances may be conducted at State or State-aided institutions, provided that (a) those observances follow rules made by the appropriate public authorities; (b) they are conducted in an equitable manner; and (c) the attendance at them is free and voluntary (RSA, 1996).

In alignment with the Constitution, (Section 7) of the South African Schools Act (Act 84 of 1996) clearly stipulates that "subject to the Constitution and any applicable provincial law, religious observances may be conducted at a public school under rules issued by the governing body if such observances are conducted on an equitable basis and attendance at them by learners and members of staff is free and voluntary" (RSA, 1996). Section 23(1) of the same Act makes provision for the creation of the requisite democratic structures and participatory processes by means of which stakeholder representatives (parents, educators, non-educators, learners in secondary schools, and even the State, as represented by the principal) could become members of school governing bodies (DoE, 1996). This provision is further emphasised in paragraph 58 of the National Policy on Religion and Education which stipulates that the governing bodies of public schools may make their facilities available for religious observances provided that this is also done on equitable basis.

In theory the intention is that governance powers and responsibilities will be distributed more equally between all stakeholders. Policies should be developed through a process of rigorous deliberation, with all stakeholders, regardless of differences including religion, having equal decision-making powers. This, according to Mncube (2009b) is the way in which democracy will manifest itself. In practice, though, one cannot ignore the reality that the processes and outcomes of any kind of human interaction are affected by the personal likes and dislikes of those involved (Ghaffar, 2009). Members of school governing bodies, like other human beings, have diverse ideas, goals, values, beliefs and opinions about the need for and nature of school governance (Van Der Merwe, Prinsloo \& Steinmann, 2003).

The complexity of schools as organisations peopled by individuals often drawn from a range of cultures but working towards a common goal - effective teaching and learning (Van der Mescht \& Tyala, 2008) - lends credence to claims like these. The different ways in which parents, educators and learners on the SGB interpret and enact their functions, participation, representation and decision-making powers in school governance matters highlight the existence of underlying historical, structural and ideological conflicts. In other words, given the role that ideological, power and value relations play in shaping forms of participation, representation and decision making, one could argue that conflicts and dilemmas are an integral part of school management (Naidoo, 2005).

The scenario presented above raised three dilemmas school principals in South African schools are faced with (Wildy, 2000). Firstly, there is the dilemma of autonomy, which requires them to provide leadership that is strong and shared. Secondly, there is the dilemma of efficacy, which demands that they provide leadership that is both democratic and efficient - in terms of the time available and effort required for decision-making. Thirdly, there is the dilemma of accountability, with school principals being held accountable for the extent to which the school complies with government or systemic policies without neglecting the need to generate local commitment.

These dilemmas constrain school principals in two ways: first, in the establishment and use of participatory decision-making structures, and second, in defending centrally developed / defined policies (Wildy, 2000). In this regard it should be borne in mind that conflicts which emerge during the policy-making and implementation phases respectively are typically played out on the field of what role-players regard as their legitimate and / or perceived powers. In a strongly unionised environment like South Africa, educators may rely on the perceived power of their unions to buffer their course for or against the implementation of a particular policy change. School governing bodies may lay claim to the powers allocated to them in the South African Schools Act (Act 84 of 1996) to further their cause, while principals may rely on the historical and allocated powers associated with their office to strengthen their position. The question thus arises, "How should principals deal with possible friction or conflict that may arise in the implementation of school policies?" 


\section{Research Method}

Due to the limited work done on the phenomenon described above, the study followed a qualitative research approach (McMillan \& Schumacher, 2014; Johnson \& Christensen, 2012), employing the phenomenological research design (Grey, 2014; Monette et. al, 2014), seldom used to study principals' experiences, choices and actions in policy implementation (Cilesiz, 2008).

Twelve school principals, who were postgraduate students at the University of Pretoria, were purposefully selected (Patton, 1990) as research participants. They participated in their private capacity, not as spokespersons of specific schools. When fieldwork took place, they were a) engaged in leadership and management training at postgraduate level; b) had been in education for at least fifteen years; c) had been exposed to various religion-in-education policies, and d) were from various religious orientations, language and cultural groupings.

Data were collected by means of narrative interviews, with school principals' stories being recorded, transcribed, analysed and interpreted. Religious issues are rarely explored scientifically. They are usually debated and discussed at a sentimental level or elevated to litigation through the courts. The use of narrative interviews enabled us to examine principals' experiences about religion that are not clouded by emotions / sentiments. They also created a platform for the principals to freely express their understanding and interpretation of the religion policy. As a result, we were able to understand what they liked or disliked about policy changes (Clandinin, Murthy, Huber \& Orr, 2010; Craig, 2010). Data were collected over a period of 4-5 months.

Ethical clearance that granted us permission to involve the principals / postgraduate students in the study was obtained from the Faculty of Education. Invitations were then directed at school principals - through direct and / or e-mail contact - who were willing to participate regardless of gender, province, historic origin and the type of schools (secondary or primary) in which they worked. The participants signed consent forms prior to interviews, which also provided permission to tape-record the interviews. We then transcribed these tapes and coded the transcripts (Clandinin \& Murphy, 2007). We transcribed principals' tape-recorded interviews and analysed transcriptions in terms of the initially identified categories (Babbie, 2014). These included principals' understanding of their mediating role in religion policy implementation.

The raw data (tape-recorded interviews), interview transcripts, interview guides, list of participants and their profiles, as well as our field notes, were audited throughout the study period to validate their accuracy and authenticity (Craig, 2010). In addition to this, we sent transcriptions to participants, asking them to correct errors of fact. This ensured that we represented them and their ideas accurately (Mertler, 2006). Finally, the study went through the program called 'Turnitin', as per the university's requirements, to ensure its originality.

\section{Results and Discussions}

Based on principals' narrative, it is evident that there are different ways in which school managers respond to conflict situations in their schools. These include resistance, sub-contracting and mediation.

\subsection{Resistance to Policy Change}

The research study referred to, defines resistance as an action or actions taken by individuals and groups that feel threatened in some or other way. If the threat is "change", resistance would hinder the process, either in the conception or in the development stage, in that its aim is the maintenance of the status quo. Inadequate information and training on the "what", "why" and "how" of a new policy could, for instance, result in opposition and / or an unwillingness to adopt the new policy. That inadequate information and training could be the reason, is suggested by one of the principals who claimed that "the policies just come and there are no people to unpack them, those that do so, interpret them to suit their interests." This claim is dubious since all of the principals who participated in this study were enrolled in post graduate courses in education management and leadership and were trained in policy and education law matters.

Contrary to the above claim, other participants suggest that they were trained, but that the training they received was insufficient and had negative impact on the procedures they used in dealing with policy implementation. Again, this is less than plausible because all the policies introduced since 1994 would have required them to act as change agents and the numerous workshops on new policy initiatives use the same broad change management frameworks. This is evident in one of the principals' narrative. According to him, they attended different courses where they were told that everyone has the right to freedom of religion, but practically, "when we come to the school, we would want learners to practice Christianity. We would emphasise the point of assembly attendance and wanted them to sing Christian songs". Lack of training on policy change did not only affect school principals, but also the SGB who are mandated to craft 
policies of their schools. In terms of Section 20 of the South African Schools Act (Act 84 of 1996), one of the functions of the governing body of the school is to develop and adopt school policies, including those pertaining to religion. Principals claimed that the training the SGB received in this regard was insufficient and negatively impacted on the procedures they used in dealing with policy crafting. In highlighting the need for SGB training, something that did not feature in any of the departmental workshops, one of the principals said,

The SGB needs to be trained on how to draw the religion policy. Their function is to formulate or adopt religion policy of the school in terms of legislations of the country. As the principal, I know the stuff, not everything but, I can refer here and there for some issues. Only to find that parent members did not want to go with what the national policy dictates in terms of religion. They wanted to go with what they felt is right and appropriate to them. They bring in that particular old fashioned religious type of belief, traditional religion; they are still stuck in that. And changing their mind-set becomes very difficult.

The implication is that, school principals in this study are passively demonstrating their resistance to proposed education policy change by either delaying or ignoring it, claiming that schools lack the requisite information on policy reform. On the other hand, they actively resist the policy by banning religious observances other than the dominant one on school premises and / or refusing permission for participation in religious observances by either learners or staff. For instance, "if a learner would come wearing the taqiyah, we would call and tell him to stop wearing it with the aim of trying to discourage them from influencing others", one of the principals stressed. In the other school "...there was this Muslim committee member who also persuaded us to be given a slot at the assembly on the argument that there are also Muslim learners in our school. We once gave him an opportunity but it was not appreciated. You could just see from their response that they do not enjoy it as they do with Christianity. We then had to discontinue".

In their narratives, principals claim that Muslim learners seem to demand special attention and privileges and they (principals) view such as potentially undermining school discipline and / or complicating school management. For example, "Muslim learners leaving school early on Fridays to attend mosque was actually a problem in terms of learning and teaching because there was no cover up time in terms of the activities that took place during their absence", one of the principals pointed out. In the latter case, lost teaching time was never recovered and learners simply had to catch up on their own. Perhaps this is why, in some schools, although that is permitted, very few of them asked to be excused on Fridays for Mosque. In either case this could result in the continued dominance of a single religion especially if it is the religion of the majority of learners or staff at the school concerned - Christianity in most South African schools.

Not only school principals but also educators were reported to resist policy changes. The principals' narratives indicate that educators in their schools did not give the teaching about religion the attention it required. Their ignorance of other religions is cited to be the contributing factor as all they knew was for example, Christianity. Some principals in this study admitted that in every religion there is something good. They are however adamant that an obstacle is for someone who belongs to the Islam faith to teach about Christianity vice versa. One of the principals describes how Life Orientation (learning area though which Religion Education is offered) educators in his school dealt with this matter, to them an unfamiliar subject.

In most cases educators are knowledgeable about Christian matters but not that of other religions. Yes, they would just indicate to learners that we have got different religions and give them their names. But, going into details about them would pose a challenge. They would therefore dwell much on Christianity to cover that period. And eh, not to say may be they want to promote Christianity, it is because most of them are Christians and they have knowledge only about Christianity.

Although these principals have a positive outlook towards differences, they could not help transform the teaching and learning about religion in their schools. Learning from the fact that these principals and the majority of educators in their schools are a product of schools in which they were exposed to for instance, one religion only, it would be very difficult for them to change their perceptions of and attitudes towards people of other religions (Ferguson \& Roux, 2003). In this manner, resistance to policy change is inevitable.

Teaching and learning material, as indicated in principals' narratives also appears to contribute much in their resistance to policy change. They signalled that a lack of teaching-learning material hinders the teaching of religion education. According to one of the principals, "even if these educators wanted to, they were deprived by the lack of teaching-learning materials to effectively teach the subject. Honestly, there are no materials to support the teachings 
except that you will have content in the text book". This, the principal claimed is not enough. "Yes, we do have text books, Life Orientation text books, and, as you know, the text book is a very small document. They may just mention different kinds of religion, nothing much".

School principals cited incapacity in terms of the drafting of a religion policy as stated in previous paragraphs. Although the principals in this study appreciated the provision that parents and learners become part of school governance, they are concerned that parent governors' potential cannot be fully utilised in this regard. They argued that most parent governors are not educated, and that those who are, do not have the time or necessary skills to assist in the policy crafting process. They also claimed that parents have no interest in school matters. "Most of our parents really are not so much interested in what is happening in schools. So, when you give their children what they do not believe in during the day...in the evening they, as parents give them something they feel is good for them. They do not care", one of the principals articulated.

In conclusion, principals in the study maintained that their position in the education structure, also as custodians of religious education - a status they acquired in the past - implied that their word, as the principal, was final. According to one of them, "to date, the parents or the SGB are not involved in the drafting of religion policy: it depends on the school principal mostly". All in all, this clearly indicates that school principals were firmly rooted in their beliefs and approaches to religion in education when the National Policy on Religion and Education was released in 2003. Such experience therefore tends to dominate their views about religion-in-education policy change hence their resistance in implementing policy change. Although principals in this study could not relate conflicts that erupted in their schools with the manner in which they deal with religion, it is evident from the data that serious conflicts manifested during implementation process. The follow-up concern would then be on the strategies they apply in managing such conflicts.

\subsection{Sub-Contracting as an Education Conflict Management Strategy}

Instead of resolving conflicts erupting from different religious interests in their schools, principals interviewed in our study avoid the conflicts by either ignoring them or by partially sub-contracting into policy directives through compliance to legislative instructions only. Sub-contracting refers to a strategy in which the school principal implements the intended educational change according to the wishes of a particular interest group or department of education.

Amongst the religious changes that came along with the South African Constitution after 1994, was that, no educator or learner may be refused appointment on religious grounds. This clause resulted in new religious experience for educators and learners of colour. In adhering to the requirements as stipulated in legislations and educational policies, indications are that the participating principals sub-contracted into the policy by tailoring admission policies of their schools to welcome learners and educators of all religions and belief systems (including Muslim, Jewish, Jehovah Witnesses, Christian and atheist) to enroll at these schools. Some "would inform non-Christian parents that their school subscribes to the Christian faith but that they should feel free to invite their religious leaders to come and address their children as part of their different religious observances", one of the principals explained. In agreeing with that recollection, the other principal stated that, "At the initial interview for appointment of a new educator at the school, we would tell him/her that this is a Christian school where the Christian faith is practised so that at least they are aware, though that does not discontinue their appointment."

The implication is therefore that should learners (or their parents) of their own free will choose to enroll at those schools however, they do so with the knowledge and understanding (and by implication, agreement) that the schools operate according to for instance, a Christian ethos and Christian values, as determined by their school governing bodies. Participation in any Christian practices or activities (including attendance of sermons, prayer, evangelism opportunities, etc) are said to be completely free and voluntary at all times. No learner and/or staff member is forced to participate in any of these against his/her will or that of the parent/guardian.

Indications are also that participating principals sub-contracted into the policy by becoming the appropriate authorities that crafted the religion policy of the schools. In so doing some of them owned the task fully while others involved the school management team (SMT). Those that involved the SGB would agree with decisions taken but would either practise the opposite or manipulate SGB elections with the intention to have people from the same faith in majority. "If I see that there is not really a good representation in the candidates coming through, I would phone a particular parent and say, I know you, and don't you want to make yourself available because I think you can add something to the governing body...? And I would phone the other parent and say, listen, I have spoken to that parent, so, you will have to nominate him", one of the principals uttered. 
According to principals' narratives, the above approach was also used to reinforce the "majority rules" principle that was adopted to avoid the possibility of conflict arising during discussions on the development of religion-in-education policies for their schools. In most of the schools it is the religious orientation of the majority of parents that determine which religion is prioritised whereas in others, it is that of learners. "Because the majority of our parents are Christians, the school ultimately decided... in principle that we are going to be subscribing to Christianity as the religion in the school. So, because the majority agreed upon that; the rest had no choice but to follow".

It is in terms of such practices that, in accordance with the Constitution, section 22 (1) of the Schools Act (84 of 1996), the participating principals adapted some clauses into their school policies and the SGB acted as a "rubber stamp" without any guarantee that such clauses would in fact be implemented. The majority of principals who participated in the study also believed that permitting, for instance Muslim learners to go to mosque without considering their lost time or sparing them a classroom was in a way, conducting religious observances on an equitable basis as well as availing their facilities for such observances.

It was discovered from the narratives also that religion-in-education policies in many schools specified that there is freedom of religion within the school but in practice, "we would encourage learners strategically to attend ... assembly, where the prayer was said, hymns were sung and Scriptures were read", one of the principals expressed. The other principal admitted that, when confronted by educators who felt that other religions must be accommodated in the school's religion policy, "we would then open the clause that says, 'everyone has the right to believe in his own religion'. The policy would be written like that, but when it comes to practice, I see all learners going to the assembly, singing, praying, and reading the Bible". Another principal was emphatic that "religion policy changed on paper. Apart from the fact that people know that it is voluntary, it is business as usual."

The study also discovered that, in an attempt to avoid conflict, other principals opted not to disclose religious orientation of their schools. Even if there was a policy, according to them, no one would bring it up in the open and say that the school was interested in children of a particular religion because the school would finally not get children. One of the principals openly admitted that in his school they never discuss the issue of religion with parents. In all "our meetings, we never thought of involving them in religious discussions". The same happens in the other principal's school, where they do not really talk about religious matters during admission, whether the school is subscribing to this kind of religion or that. "We do not tell parents that we are Christians, but the way things are done says it all. To be honest with you that does not happen even to date. We just admit the child, unless there are cases where a parent would tell you that his child must be excused from the assembly".

It is conclusive therefore that a number of schools adapted some of the clauses from the South African Constitution (Act 108 of 1996), South African Schools Act (Act 84 of 1996) and the national religion policy into their school policies, not necessarily with the intention of applying them in their daily school lives, but to technically or administratively comply with the directives of departments of education. Compliance is therefore simply administrative. In other words, the wishes of certain stakeholder groupings still prevail when it comes to implementation of religion policy change. Practices such as these do not only make the conflict destructive, but also increase or sharpen differences that lead to irresponsible and harmful behaviour. It is instances like these that made us ask ourselves whether or not there is an alternative strategy for dealing with this kind of conflict in schools in an amicable way. It is on this question that we propose the use of mediation.

\subsection{Mediation as an Education Conflict Management Strategy}

Most of conflict management theories represent an "outsider perspective" on change, based on the assumption that agents external to the organisation, such as consultants, could make the organisation change into what they want it to be - the only trick is finding the right approach (Seel, 2005). Contrary to this perspective, Fullan (2001) maintains that change cannot be managed, '.. it can be understood and led, but it cannot be controlled'. Conflict, in contrast, cannot be left unchecked: it needs to be managed by means of a strategy that lends itself to a resolution in a manner that would satisfy all parties involved. It is behind Fullan's perspective that we base our proposal.

Mediation is defined differently depending on a theorist's point of view at a particular time. Moore (2003), for example, defines mediation as an intervention in a negotiation or conflict by an acceptable third party who has limited or no authoritative decision-making power but who could assist the involved parties in voluntarily reaching a mutually acceptable settlement of issues in dispute. Goodpaster (1997) regards it as a problem-solving negotiation process in which an outsider, impartial neutral party works with disputants to assist them to reach a satisfactory agreement. In a different view, Bush and Folger (1994) define it as a process in which a third party works with conflicting parties to help them change the quality of their interaction from negative and destructive to positive and constructive. 
All these three definitions mention a third party, a mediator who could serve different purposes. Because of this, mediation is often equated with negotiation. While there are some similarities between these two processes, they are not exactly the same. In a process focusing on mediation, parties with apparently incompatible demands hand over only the dispute resolution process, not the dispute itself, to the mediator (National Open University of Nigeria, 2006). In contrast, the purpose of a negotiation process is to resolve the dispute, i.e. to reach common ground and / or a compromise between disputing parties.

Other forms of conflict resolution are often confused with mediation: these include arbitration, case evaluation and litigation. Mediation differs from arbitration in that a mediator makes no decisions as to how the conflict should be resolved whereas the arbitrator does; rather, the mediator simply guides the parties towards determining a resolution themselves. Mediation differs from case evaluation in that the mediator draws no conclusions about the value of a claim and there is no penalty if the mediator is unsuccessful; a case evaluator makes value decisions and can be penalised for making a wrong decision. Lastly, mediation differs from litigation in that it is quicker and less expensive; moreover, it allows disputing parties to work out their own solutions in private rather than having an unknown result imposed on them by a judge or jury in the course of a lengthy, expensive and formal process (National Open University of Nigeria, 2006). Unfortunately the latter - litigation - seems to have become the norm in many school-related conflict cases in South Africa.

In this article mediation is viewed as a process in which conflict itself is transformed from a negative and destructive interaction to a positive and constructive one (Bush \& Folger, 1994, 2005). From an education management perspective this implies that the principal, being "an insider", negotiates with various interest groups to try and reconcile differences and to find a way in which implementation of policy change acknowledges the interests of various stakeholders. Mediation serves two purposes, namely problem-solving and transformative mediation (Bush \& Folger, 1994, 2005). Our focus in this article is to present transformative mediation as a leadership strategy for conflict resolution in schools with a view to comparing and relating it to the South African school governance context.

\subsection{Transformative Mediation}

As the name implies, the primary purpose of transformative mediation is the transformation of opposing parties' relationship with one another - usually from negative and destructive interaction to interaction that is positive and constructive. The latter kind of interaction is meant to benefit everybody concerned: disputants would derive personal, societal and public benefits from such a transformation simply because the quality of their interaction would have changed (Bush \& Folger, 2005). Noce (1999) calls this kind of mediation relational transformative mediation.

The transformative mediation approach tends to be process-oriented, with success being defined in terms of improvements in disputants' personal clarity and interpersonal understanding (Bush \& Folger, 1994, 2005; Folger \& Bush, 1996; Noce, 1999). The premise on which transformative mediation rests is that individuals in conflict should seek to improve the quality of their relationship with their opponents, first by seeking a better understanding of themselves and of the opposing party and then by creating shared meanings. Both parties must, however, strive towards the same goals, namely empowerment (growth in strength of self), and recognition (concern for others). Crucial to the success of this approach is opponents' realisation that they first need to understand themselves before they attempt to understand others. Like any other transformative process, this takes time (Fullan, 2007). The mediator's task, therefore, is not to seek resolution of the immediate problem but rather to foster opportunities for empowerment and recognition.

Transformative mediators encourage disputants to confront their own issues and to seek their own solutions. Informing the latter approach is the assumption that accepting responsibility for their own emotions and solutions make disputants more aware of their own position and values. This awareness, in turn, enables them better to deal with difficulties they are facing when they seek to see and understand another person's point of view (Bush \& Folger, 2005; Folger, 2002; Noce, 1999).

Wong (1998), phrasing the same idea somewhat differently, moots that change begins within the persons concerned in their hearts, heads, and hands. According to Wong (1998), transformative mediation is essentially about helping people understand the problems they are facing, helping them to manage these problems, and even teaching them how to learn to live with their problems. Rather than looking at conflict as a dispute which needs to be settled, Wong argues, transformative mediators regard conflict as an integral part of human interaction, which is why they focus on the way(s) in which disputants interact with each other during mediation rather than on the outcome of the dispute.

Instead of emphasising or prioritising personal or opposing views, transformative mediators help parties recognise and exploit opportunities for moral growth inherent to conflict (Bush \& Folger 1994). In doing so, they move disputants 
from a position where they feel unsettled, confused, fearful, disorganised, or unsure, to one in which they are calmer, clearer, more confident, more focused or more decisive. Once this happens, disputants are able to identify the resources available to them and / or the resources they need to make informed choices. They come to realise that they hold something that is of value to the opponent, that they can communicate effectively with the opponent, and that they can utilise their resources to pursue their goal(s) (Bush \& Folger, 1994, 2005). More importantly, they are enabled to improve their own skills in conflict resolution: they learn how to listen, communicate, analyse issues, evaluate alternatives and make decisions more effectively than they could before and, because of this, they begin to be more responsive to others (Folger, 2002; Noce, 1999).

Disputants' newly-acquired ability to see and understand the opponents' point of view - to understand how they define the problem and why they seek the solution that they do - either enables parties in conflict to reach a mutually satisfactory solution, or suggests other approaches for handling the situation. At this stage, disputants move from being self-absorbed, defensive, suspicious, and unable to step outside their own views to being more attentive to the opponent, more open and more willing to accept the other's point of view (Bush \& Folger, 1994, 2005).

In working with disputants, transformative mediators may make suggestions about processes and ask questions, but they do not direct the conversation, nor do they suggest settlement options (Bush \& Folger, 2005). All in all, the transformative mediation process helps disputants to recapture their sense of competence and connection, to reverse the negative conflict cycle, to re-establish constructive interaction, and to move forward on a positive footing, all with the mediator's help (Bush \& Folger, 2005).

...the stronger I become the more open I am to you. The more open I am to you, the stronger you feel, the more open you become to me, and the stronger I feel. Indeed the more open I become to you, the stronger I feel in myself, simply because I am more open; that is, openness not only requires but creates a sense of strength, of magnanimity (Bush \& Folger, 2005).

In the South African education context inclusion and trust are key transformation principles, with the core values embedded in a highly political, value-led contingency model of transformational school leadership. Entrepreneurialism, the improvement of academic achievement, and the ethics of care, compassion and social justice are key features of this model (Day, 2005). Transformation and its mediation would therefore entail more than simply putting the latest policy in place: it would require intensive action sustained over several years to transform - physically and attitudinally - the cultures of classrooms, schools, districts and universities (Fullan, 2007).

Implementing school policies in an inclusive context poses many challenges to school principals, especially in terms of their leadership role (Hallinger, 2010). Key among these is the challenge of effectively interpreting and translating national and provincial policies into school policies. Given the different interests and literacy levels of the relevant stakeholder groupings, interpretations and translations are bound to differ and, without proper leadership, conflicts generated by these differences might result in ineffective or delayed implementation of important policies. This is what happened in the case of the new religion policy for schools in South Africa: public involvement in decision-making regarding the inclusion or not of different religions in the national curriculum generated extensive public debate and resulted in delayed implementation.

Many years of political disempowerment have left some role players in school governing bodies feeling defensive, suspicious, fearful, confused and unable to step outside their own views - including cultural or religiously held views. Often they lack the ability to be attentive or to be more open and willing to accept the other because their views are informed by mistrust and suspicion. In part this is the result of parent representatives' feelings that they are being marginalised because of their low educational levels. They are therefore more susceptible to accepting what people in positions of power demand or prescribe and they are not able to voice their own opinions. Transformative mediation has the potential to help these individuals develop their latent abilities to engage constructively in resolving conflict.

Very often literature on mediation refers to a third 'objective or neutral' party that is brought into the conflict situation to assist in its resolution (Schellenberg, Parks-Savage \& Rehfuss, 2007). This is true for many of the different forms of mediation. Based on Fullen's (2007) claim, we would, however, like to argue that within transformative mediation the school principal is ideally situated within the school governing body (SGB) to perform the task of a transformative mediator, provided that he is well-trained in this strategy. We base our argument on the fact that in his position as the head of the school, an ex-officio member of the education department as well as an official member of the SGB, the school principal is in an ideal position to understand educational change in the way the school experiences it. Because of this, he stands a good chance to lead it in an amicable way. 
To illustrate our argument, we chose a specific theoretical mediation model, Feuerstein's Mediated Learning Experience (MLE) model (Figure 1), as our frame of reference. Both the Feuerstein model and our exploration focus on mediation within an educational context. While Feuerstein focuses on the mediation of student learning we focus on the mediation of conflict by school principals.

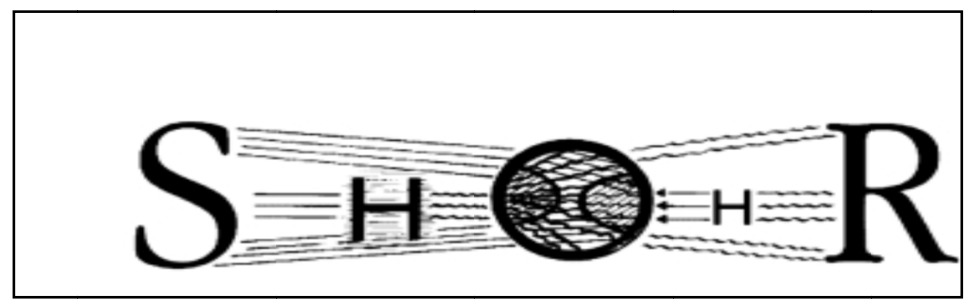

Figure 1. The Mediated Learning Experience (MLE) Model

Source: Feuerstein (1991) in Chang (1993)

For the purpose of our argument the $\mathrm{S}$ in the figure refers to the stimulus, the $\mathrm{H}$ to the principal as the mediator, the $\mathrm{O}$ to stakeholder groupings, and the $\mathrm{R}$ to the response of the individuals.

According to Feuerstein's (1980) theory, mediation is the:

... Way in which stimuli emitted by the environment is transferred by a "mediating" agent, usually a parent, sibling or other caregiver. This mediating agent, guided by his intentions, culture, religion and emotional investment, selects and organises the world of stimuli for the child... Through the process of mediation, the cognitive structure of the child is affected.

By "organising the world of stimuli" in order to change the child's "cognitive structure", the mediator is, in fact, mediating the child's learning experience. Feuerstein (1991) in Chang, (1993) defines a mediated learning experience (MLE) as the "quality of interaction between the organism and its environment". According to Feuerstein and Louis (1990), a mediator intervenes between the stimulus, the organism, and the response so as to interpret, regulate, elaborate, and reinforce a learner's experience (see Figure 1). Applied to the context of school leadership, MLE would refer to the kind of experience provided by a school principal who understands the interests, needs, and capacities of various stakeholder groupings and who can play an active role in the creation of two-way interaction (Chang, 1993). Unlike an external agent who handles change from an "outsider perspective", the school principal cannot leave conflict unchecked but he works with the conflicting parties to resolve the conflict in a manner that would satisfy all parties involved. Such a principal, according to Sergiovanni (2001), would provide

Leadership for meaning, leadership for problem solving, collegial leadership, leadership as shared responsibility, leadership that serves school purposes, leadership that is tough enough to demand a great deal from everyone, and leadership that is tender enough to encourage the heart. These are the images of leadership we need for schools as communities.

From the above perspective, we suggest that much more attention be directed at the training of principals in transformative mediation skills to help them understand their own assumptions, values and beliefs and to realise how these may hinder the implementation of policies that could lead to transformed schools.

\section{Conclusion}

It is evident from principals' narratives that not only school principals but also educators resisted policy change. Insufficient information and training, lack of teaching material and human resource were blamed for such resistance. Consequently, they ignore the policy in favour of maintaining the status quo. When confronted by tensions and dilemmas, the data indicates that school principals either ignore or partially sub-contract into the policy and selectively adopt certain legislative clauses for technical or administrative purposes that may help them align with the directives of departments of education, not necessarily for their application to the day-to-day running of their schools.

Another conclusion, based on the same data, is that school principals do not acknowledge or use transformative mediation as a leadership strategy for conflict resolution in existing religious context in schools. There seem to be two 
possible reasons for this. One, principals have not received training or are not skilled in the use of transformative mediation. Two, although they had received training up to a post-graduate level and had been exposed to conflict management and resolution theory, they lack the requisite set of knowledge, skills and attitude particular to transformative mediation processes. It could be inferred, therefore, that the skill of applying their knowledge of this strategy in their own schools may not have been developed adequately.

In conclusion, we would argue that application of mediation as a leadership strategy in handling disputes and solving problems from within holds potential benefits for fields such as education. This creates the opportunity for higher education institutions to reconstruct their teaching and / or training to include issues of conflict - to weave mediation, transformative mediation in particular, into the fabric of educational leadership curricula, pedagogies, programmes, and policies.

\section{References}

Abdool, A., Potgieter, F., Van der Walt, J. L., \& Wolhuter. (2007). Inter-religious dialogue in schools: A pedagogical and civil unavoidability. HTS, 63(2), 543-560. http://dx.doi.org/10.4102/hts.v63i2.211

Babbie, E. (2014). The basic of social research (6th Ed.). USA: Wadworth

Bush, R. A. B., \& Folger, J. P. (2005). The Promise of Mediation. The Transformative Approach to Conflict. New and Revised Edition. San Francisco: Jossey-Bass.

Bush, R. A. B., \& Folger, J. P. (1994). The promise of mediation. San Francisco: Jossey-Bass.

Chang, C. W. (1993). An Investigation into Teachers' Mediation with Junior College Students' Learning English in Taiwan. Department of Foreign Languages, 97-135.

Cilesiz, S. (2008). Educational Computer Use in Leisure Contexts: A Phenomenological Study of Adolescents' Experiences at Internet Cafes. American Educational Research Journal, 46(1), 232-274. http://dx.doi.org/10.3102/0002831208323938

Chisholm, L. (2005). The politics of curriculum review and revision in South Africa in regional context. Compare: A Journal of Comparative and International Education, 35(1), 79-100. http://dx.doi.org/10.1080/03057920500033563

Clandinin, D. J., \& Murphy, S. (2007). Looking ahead: Conversations with Elliot Mishler, Don Polkinghorne, and Amia Lieblich. In Clandinin, D. J. (ed.), Handbook of narrative inquiry: Mapping a methodology. Pp 632-650. Thousand Oaks, CA: Sage Publications. http://dx.doi.org/10.4135/9781452226552.n24

Clandinin, D. J., Murphy, M. S., Huber, J., \& Orr, A. M. (2010). Negotiating Narrative Inquiries: Living in a Tension-Filled Midst. The Journal of Educational Research, 103, 81-90. http://dx.doi.org/10.1080/00220670903323404

Craig, C. J. (2010). Research on the Boundaries: Narrative Inquiry in the Midst of Organised School Reform. The Journal of Educational Research, 103, 123-136. http://dx.doi.org/10.1080/00220670903323883

Day, C. (2005). Principals who sustain success: Making a difference in schools in challenging circumstances. International Journal of Leadership in Education, 8, 273-290. http://dx.doi.org/10.1080/13603120500330485

Department of Education. (2001). Manifesto on Values, Education and Democracy. Pretoria: Government Printer.

Department of Education. (2003). National Policy on Religion and Education. Pretoria. Government Printer.

Ferguson, R., \& Roux, C. (2003). Mediation in the context of teaching and learning about religion in tertiary education. South African Journal of Education, 23(4), 292-296.

Feuerstein, R. (1980). Instrumental Enrichment. Baltimore: University Park Press.

Feuerstein, R., \& Louis, F. (1990). Cognitive perspective for counselling and psychotherapy. International Journal of Cognitive Education and Mediated Learning, 1(2), 143.

Folger, J. P. (2002). Mediation Goes Mainstream: Taking the Conference Theme Challenge. Pepperdine Dispute Resolution Law Journal, 3, 1-9. http://dx.doi.org/10.1002/crq.3900130403

Folger, J. P., \& Bush, R. A. B. (1996). Transformative Mediation and Third-Party Intervention: Ten Hallmarks of a Transformative Approach to Practice. Mediation Quarterly, 13, 263-278.

Fullan, M. (2007). (ed.). The New Meaning of Educational Change (4 ${ }^{\text {th }}$ ed.). Published by Teachers College Press: 
Teachers College, Columbia University, New York and London.

Fullan, M. (2001). Leading in a Culture of Change. San Francisco: Jossey-Bass.

Ghaffar, A. (2009). Conflict in Schools: Its Causes \& Management Strategies. Journal of Management Sciences, III(II), 212-227.

Grey, D.E. (2014). Doing research in real world. London: Sage.

Goodpaster, G. (1997). A guide to negotiation and mediation. New York: Transnational Publishers Inc.

Hallinger, P. (2010). Making education reform happen: is there an 'Asian' way? School Leadership \& Management, 30, 401-418. http://dx.doi.org/10.1080/13632434.2010.502524

Joubert, R., \& Prinsloo, S. (2009). The Law of Education in South Africa (2nd Ed.). Van Schaik Publishers.

Johnson, B., \& Christensen. L. (2012). Educational Research (4th Ed.). Quantitative, Qualitative, and Mixed Approaches. Thousand Oaks, CA: Sage Publications. Inc.

McMillan, J., \& Schumacher, S. (2014). Research in education: Evidence based inquiry (7th ed.). England: Pearson Education

Monette, D., Sullivan, T., \& De Jong, C. (2014). Applied social research: A tool for human services. USA: Cengage Learning.

Mertler, C. A. (2006). Action Research.Teachers as Researchers in the Classroom. SAGE Publications. Thousand Oaks. London. New Delhi.

Moore, C. M. (2003). The mediation process: Practical Strategies for Resolving Conflict (2nd Ed). San Francisco: Jossey-Bass. In Mourier, P., \& Smith, M. E., (eds.), 2001. Conquering organizational change: How to succeed where most companies fail. Atlanta: CEP Press.

Mkhatshwa, S. (1998). Opening address on "Multi-religious Education in South Africa". Problems and prospects in a pluralistic society. Published by the Research Institute for Theology and Religion, University of South Africa, Pretoria.

Mncube, V. (2009b). The perceptions of parents of their role in the democratic governance of schools in South Africa: Are they on board? South African Journal of Education, 29, 83-103. http://dx.doi.org/10.1590/S0256-01002009000100006

Naidoo, J.P. (2005). Educational Decentralisation and School Governance in South Africa: from Policy to Practice. $\mathrm{PhD}$ thesis presented to the Harvard Graduate School of Education, Harvard.

National Open University of Nigeria. (2006). Theories in Conflict Management. Course Guide. Victoria Island, Lagos.

Noce, D. J. (1999). Seeing Theory in Practice: An Analysis of Empathy in Mediation. Negotiation Journal, 15, 271-301. http://dx.doi.org/10.1111/j.1571-9979.1999.tb00196.x

Patton, M. Q. (1990). Qualitative evaluation and research methods (2nd ed.). Thousand Oaks, CA: Sage Publications. Inc.

Republic of South Africa. (1996). The Constitution of the Republic of South Africa. Pretoria: Government Printer.

Republic of South Africa. (1996). South African Schools Act (Act 84 of 1996). Pretoria: Government Printer.

Roux, C. (2001). Religion in Education in South Africa: Myth or reality? Panorama. International Journal of Comparative Religious Education and Values, 13(1), 17-26.

Schellenberg, R., Parks-Savage, A., \& Rehfuss, M. (2007). Reducing levels of elementary school violence with peer mediation. Professional School Counselling, 10, 475-48. http://dx.doi.org/10.5330/prsc.10.5.q786607713v5q044

Sergiovanni, T. J. (2000). The lifeworld of leadership: creating community and personal meaning in our schools. San Francisco: Jossey-Bass.

Seel, R. (2005). The Nature of Organisational Change, Higher Education Academy, Retrieved from $\mathrm{http}: / /$ www.heacademy.ac.uk/resources.asp?process=full_record\&section=generic\&id=547

Van Der Merwe, H. M., Prinsloo, I. J., \& Steinmann, C. F. (2003). An Educator's guide to school management skills. Published by Van Schaik publishers, Pretoria.

Van Der Mescht, H., \& Tyala, Z. (2008). School principals' perceptions of team management: a multiple case-study of secondary schools. South African Journal of Education, 28, 221-239. 
Wildy, H., \& Louden, W. (2000). School Restructuring and the Dilemmas of Principals' Work. Educational Management and Administration, 28(2), 173-184. http://dx.doi.org/10.1177/0263211X000282006

Wong, K. (1998). Culture and Moral Leadership in Education. Peabody Journal of Education, 73, $106-125$. http://dx.doi.org/10.1207/s15327930pje7302_5 